\title{
Clube de Robótica: autonomia e protagonismo juvenil por meio de atividade complementar na escola
}

\author{
Josualdo Dias ${ }^{1,2}$, Débora Abdalla ${ }^{1}$, Hugo Saba ${ }^{2}$ \\ ${ }^{1}$ Grupo de Pesquisa e Extensão Onda Digital - Universidade Federal da Bahia (UFBA) \\ Av. Adhemar de Barros Campus Ondina - 40170-210 - Salvador - BA - Brasil \\ ${ }^{2}$ Núcleo de Pesquisa Aplicada e Inovação - Universidade do Estado da Bahia (UNEB) \\ Rua Silveria Martins, 2555, Cabula - 41150-000 - Salvador - BA - Brasil \\ \{josualdo.dias, abdalla\}@ufba.br, hcardoso@uneb.br
}

\begin{abstract}
The obsolescence of the school environment, there is no sense of that students demonstrate their skills and talents, reflect the need for evidence and autonomy to become own knowledge builders, through practices involving innovative methodologies, correlating with use of technological resources for maturity and enthusiasm in their discoveries. From the context it is sought to discuss how the practices developed in a robotics clubs as a complementary activity, through reports of experiences, reveal knowledge and skills inherent to the students, promoting the development of youth protagonism.The contribution that complementary practice of the BahiaBot robotics club proposed in the scientific production, collaborating in the development and construction of the knowledge of the students of the technical course in Informatics of Professional Education.
\end{abstract}

Resumo. A obsolência do ambiente escolar, no sentido de não permitir que estudantes demonstrem suas capacidades e talentos, reflete a necessidade de se evidenciarem com protagonismo e autonomia para que possam tornar-se construtores do próprio conhecimento, através de práticas envolvendo metodologias inovadoras, correlacionando-se com o uso de recursos tecnológicos para amadurecimento e entusiasmo em suas descobertas. A partir desse contexto buscase discutir como as práticas desenvolvidas em um clube de robótica como atividade complementar, por meio de relato de experiência, revelam conhecimentos e habilidades inerentes aos estudantes, promovendo o desenvolvimento do protagonismo juvenil. Evidencia-se a contribuição que a prática complementar do clube de robótica BahiaBot propôs na produção científica, colaborando no desenvolvimento e construção do conhecimento dos alunos do curso técnico em Informática da Educação Profissional.

\section{Introdução}

O protagonismo se refere a um indivíduo que desempenha um papel principal. No âmbito educacional, o protagonismo é expresso de forma mais ampla, pois se entende que não se pode trabalhar no campo educacional sem que haja um trabalho conjunto. Nessa abordagem, busca-se a compreensão do protagonismo expresso por jovens, para o seu desenvolvimento social e educacional, que por sua vez caracteriza a autonomia no sentido de provocar a construção do próprio conhecimento 
VI Congresso Brasileiro de Informática na Educação (CBIE 2017)

Anais do XXIII Workshop de Informática na Escola (WIE 2017)

Para Assmann (1998), o panorama educacional brasileiro é desolador, especialmente na escola pública de primeiro e segundo grau [Assmann 1998]. Ele relaciona a desolação do panorama educacional à desmotivação do professorado sob reflexo do ambiente escolar, e relata que as lutas pela redignificação do profissional não englobam somente questões pedagógicas de reencantamento da educação e qualidade de ensino. Segundo Assmann (1998), reencantar a educação significa evidenciar a ação educativa como ensejamento e produção de experiências de aprendizagem. O desencantamento dos alunos, segundo Caldas e Hübner (2001), com o aprender na escola ao passo que avançam os anos escolares, apontam que, "a concepção de que aprender na escola é "Muito legal" diminuiu com a progressão das séries escolares e incidência de alunos que "não gostam de aprender na escola", aumenta gradualmente com a elevação das séries escolares" [Caldas and Hübner 2001].

O desenvolvimento de práticas que contextualizem a realidade dos estudantes contribui com a liberdade de pensamento, uma vez que o indivíduo busca na sua experiência uma real significação para o que é ensinado. As experiências do indivíduo, que segundo Paulo Freire (1996) deve ser o núcleo da formação da autonomia em si, e essa se constrói de forma gradativa no processo decisório de cada sujeito. A robótica em seu contexto interdisciplinar, de modo que são realizadas práticas que mesclam disciplinas técnicas ou não, possibilita a formação de alunos com habilidades específicas e concretas em diferentes eixos cognitivos, por meio das suas experiências e vivências em sociedade. Tecnologias e conhecimentos integram-se para produzir novos conhecimentos que permitem compreender as problemáticas atuais e desenvolver projetos, em busca de alternativas para a transformação do cotidiano e a construção da cidadania [Almeida 2005]. Possibilitar a aprendizagem através uma nova tecnologia, como a robótica, em concordância com outras áreas do conhecimento, busca gerar estímulos que possam melhorar o aprendizado nas atividades escolares, incentivar a pesquisa, mesmo na educação básica, e demonstrar aptidão dos alunos de escolas públicas ou privadas, para a área da computação, engenharias ou qualquer outra, em virtude da robótica ser uma área interdisciplinar.

Por meio dessa ambientação, defende-se a robótica como um meio para o desenvolvimento dos estudantes, uma vez que desperta a curiosidade e interesse em aprender e aplicar a robótica. Práticas como essas possibilitam ao estudante evidenciar habilidades e desenvolver competências, como indicado por Benitti (2012), demonstrando que a robótica educacional tem um enorme potencial como uma ferramenta de aprendizagem, incluindo o apoio ao ensino de disciplinas que não estão relacionadas com a área da robótica diretamente [Benitti 2012], ainda que seja em um contexto extracurricular.

Embora se trabalhe com as terminologias para tais práticas, como extracurricular e extraclasse, adotamos o termo atividade complementar. Imídio Nérici (1967) sugere que a denominação mais precisa para as atividades de cunho extraclasse [Nérici 1967], seja de atividades complementares, destacando que essas se destinam a, por exemplo, complementar as atividades que são vistas pelos alunos com preferência e interesse.

Práticas complementares possibilitam o trabalho de temáticas que muitas vezes não cabem no currículo escolar ou torna-se inviável em meio à metodologia empregada em sala de aula. Contudo, é inerente à essas atividades uma troca, um complemento, mesmo que não estejam diretamente ligadas. Despertar no estudante o interesse em aprender a aprender, sem que se evidencie uma obrigação, simplesmente pela vontade 
VI Congresso Brasileiro de Informática na Educação (CBIE 2017)

Anais do XXIII Workshop de Informática na Escola (WIE 2017)

e motivado pelo desejo de trabalhar em equipe para desenvolver competências, solucionar problemas, em que se diverte e aprende fazendo (hands-on), prática destacada por [Bustamante 2003]. As organizações estudantis que desenvolvem atividades complementares, como o Clube de Robótica (CR), possibilitam, além do protagonismo (autonomia e autoconfiança) expresso por Freire (1996), a exploração de novos interesses, principalmente em STEM (sigla em inglês que significa Ciência, Tecnologia, Engenharia e Matemática) e adquirem novos conhecimentos, reconhecem habilidades, desenvolvem competências e compartilham experiências. O objetivo deste artigo é apresentar e discutir a aplicação da robótica educacional por meio de ação complementar de um clube de robótica em uma escola da Educação Profissional.

Este artigo está organizado em quatro seções, além da seção inicial de introdução. A seção 2, Clube de Robótica como atividade complementar, faz uma abordagem em relação ao clube e o desenvolvimento de atividades que aproximam o ambiente escolar da vida autêntica em sociedade. Clube de Robótica: autonomia e protagonismo, seção 3, apresenta-se como o clube de robótica traz para os estudantes envolvidos uma possibilidade de aprendizado diferenciado. Na seção 4, Discussões e Reflexões são sistematizadas em algumas observações e resultados que colaboram na defesa da robótica como prática educacional importante para o protagonismo juvenil. Por fim, na seção 5 são colocadas as considerações finais sobre este artigo.

\section{Clube de Robótica como Atividade Complementar}

Atividades complementares através de clubes, como um Clube de Robótica, unem estudantes com interesses em comum, mesmo que não dominem as práticas desenvolvidas nessas atividades, conforme indica Fassbinder (2012), que percebeu a necessidade da criação de atividades complementares diferenciadas para ensinar sobre programação de computadores [Fassbinder 2012], paralelamente ao ensino formal e tradicional, mas que estimulasse os estudantes a seguirem seus estudos com prazer e motivação. As atividades e disciplinas complementares podem expandir os horizontes das relações educativas especialmente para os jovens. Essa expansão se justifica pela utilização de estratégias e metodologias de ensino que provoque um atrativo para aprender e estimular o aprendizado, diferente das metodologias tradicionais.

Ter acesso à informação de forma fácil , rápida e diversificada, através da internet, pode ser um fator de desinteresse dos estudantes em buscar o professor como fonte para sua aprendizagem. Fazer conexão entre as aprendizagens escolares com as vivências do indivíduo é de extrema importância e é um dos desafios da educação [Yus and de Moraes 2002]. Nesse sentido, as práticas complementares representam um importante estimulo por apresentar, em alguns modelos dessas práticas, processos que buscam no estudante formação de competências educacionais e sociais como, iniciativa, autoconfiança, responsabilidade.

Ser capaz de se ver como agente principal da sua própria história, demonstra o protagonismo que é desenvolvido nos estudantes que participam de ações complementares. Esses aspectos são desenvolvidos nas práticas de um Clube de Robótica, onde além do conhecimento tecnológico advindo dos projetos que os estudantes constroem, esses podem exercer um papel de cidadania quando os projetos visam propor uma solução para a vida em comunidade. Assim, notamos que o estudante tende a relacionar seu exercício 
VI Congresso Brasileiro de Informática na Educação (CBIE 2017)

Anais do XXIII Workshop de Informática na Escola (WIE 2017)

de cidadão e sua capacidade de se mobilizar socialmente, o que conceitua protagonismo juvenil.

\begin{abstract}
"Protagonismo juvenil é a participação do adolescente em atividades que extrapolam os âmbitos de seus interesses individuais e familiares e que podem ter como espaço a escola, os diversos âmbitos da vida comunitária igrejas, clubes, associações e até mesmo a sociedade em sentido mais amplo, através de campanhas, movimentos e outras formas de mobilização que transcendem os limites de seu entorno sóciocomunitário" [Costa and Vieira 2000].
\end{abstract}

As práticas sociais que desenrolam-se de um CR, sendo desenvolvidas a partir de espaços como uma escola ou universidade vão ao encontro do pensamento de Rubens Alves (1999), que trás que o objetivo das escolas e universidades é contribuir para o bem estar do povo [Alves 2000]. Por isso, sua tarefa mais importante é desenvolver, nos cidadãos, a capacidade de pensar. Para Almeida (2005):

"Ao desenvolver projetos em sala de aula, é importante levantar problemáticas relacionadas com a realidade do aluno, cujas questões e temáticas em estudo partem do conhecimento que ele traz de seu contexto e buscam desenvolver investigações para construir um conhecimento científico que ajude este aluno a compreender o mundo e a conviver criticamente na sociedade" [Alves et al. 2005].

Para Charão (2015), atividades como as desenvolvidas em clubes, que apresentam abordagens não-formais têm sido empregadas para complementar e impulsionar o ensino formal. Assim a criação de clubes de computação, como ação extensionista voltada para escolas visam disseminar fundamentos de computação [Charao et al. 2015]. Nesse sentido, destacam-se outros objetivos da prática complementar, segundo Imídio Nérici (1967):

" $1^{\mathrm{o}}$ Atender às necessidades de desenvolvimento do adolescente, principalmente, com relação aos aspectos de expansão, expressão, participação e afirmação da sua personalidade.

$2^{\mathrm{o}}$ Favorecer o desenvolvimento emotivo.

$3^{0}$ Favorecer a formação social e moral.

$4^{\mathrm{O}}$ Favorecer a formação cívica.

$5^{\mathrm{O}}$ Favorecer o desenvolvimento intelectual.

$6^{\mathrm{O}}$ Vitalizar o ensino.

$7^{\circ}$ Favorecer a manifestação vocacional.

$8^{\mathrm{o}}$ Favorecer o aparecimento de líderes.

$10^{\circ}$ Favorecer o desenvolvimento do espírito de iniciativa e o senso de responsabilidade.

$11^{\circ}$ Formar para a vida democrática.

$12^{\circ}$ Favorecer o estudo autônomo.

$13^{\circ}$ Promover melhores relações entre educando, seus colegas, professores, e entre estes e a família.

$14^{\circ}$ Favorecer a recreação.

$15^{\circ}$ Favorecer a integração da escola na comunidade." [Nérici 1967. Pág: 33-44] 
VI Congresso Brasileiro de Informática na Educação (CBIE 2017)

Anais do XXIII Workshop de Informática na Escola (WIE 2017)

Os objetivos apresentados estão implícitos nas ocorrências do CR como atividade complementar em vários níveis, uma vez que promove a reflexão da vida em sociedade com a própria realidade, de maneira a aproximar o ambiente escolar, de forma gradual, as suas vivências, ao passo que vão proporcionando aos alunos oportunidades de reconhecer em suas atividades no clube as experiências de dentro e fora da escola.

\section{Clube de Robótica: autonomia e protagonismo}

As experiências do Clube de Robótica BahiaBot, na qual fazem parte estudantes da Educação Profissional Integrada ao Ensino Médio do curso técnico em informática, demonstram que os encontros do clube concentraram-se em explorar as experiências dos estudantes no processo de construção dos robôs, fazendo a inserção de aspectos teóricos de forma sucinta e lúdica. Nas ações do clube se busca elaborar propostas de projetos robóticos e de automação que exerçam benefícios ao ambiente escolar e a comunidade, através de discussões que mesclam teoria e prática.

O processo de implantação do Clube de Robótica BahiaBot ocorreu junto às atividades desenvolvidas pelo projeto de intervenção Robótica Básica e Educacional [Dias et al. 2015], aprovado pela Fapesb no ano de 2013 em edital de Popularização da Ciência para Educação Científica, pelo Núcleo de Pesquisa Aplicada e Inovação (NPAI/UNEB) iniciado em 2014. Entre as etapas de aplicação do projeto de intervenção, ocorreu formação de equipes para competições com um grupo de estudantes do Curso Técnico em Informática da modalidade Educação Profissional Integrada ao Ensino Médio no Centro Territorial de Educação Profissional do Litoral Norte e Agreste Baiano em Alagoinhas - Bahia (CETEP/LNAB). A nomenclatura de equipe de competição foi descartada por inferir a ideia de ações exclusivamente voltadas às competições, e assim os estudantes selecionados integraram-se ao Clube de Robótica.

A seleção dos estudantes para o CR ocorreu com base no desempenho e interesse pelo campo da robótica, que foi percebido através das ações em sala de aula do projeto de intervenção. Os alunos que demonstraram maior interesse, com base nas avaliações de conhecimentos, questionários aplicados, frequência, observação das turmas na primeira etapa do projeto de intervenção, foram convidados à participar de oficinas extras, encontros do CR voltados integralmente para o desenvolvimento de projetos robóticos para construção do conhecimento, promoção do pensamento científico e participação em eventos científicos. As ações do clube de robótica, embora perpassem pelas metodologias que o projeto de intervenção busca desenvolver em sala de aula (ações interdisciplinares e método PBL), envolvem efetivamente práticas em que aspectos de aprendizagem colaborativa e ativa são necessários para o desenvolvimento dos projetos.

No levantamento feito através dos questionários, evidenciamos aspectos para avaliar o interesse em permanecer no Clube de Robótica e desenvolver os trabalhos propostos. Nesse levantamento foi possível observar as pretensões dos estudantes após a conclusão do Curso Técnico em Informática.

A expectativa dos estudantes em relação a sua própria contribuição na ação complementar foi questionada e identificamos outras atitudes que demonstrassem o interesse nas atividades e o reflexo do pensamento em equipe, principalmente com as ações de identificação de problemas para formação de desenvolvimento prático. As respostas ao questionamento sobre a expectativa de participação pode ser observada na Tabela 1 (O 
VI Congresso Brasileiro de Informática na Educação (CBIE 2017)

Anais do XXIII Workshop de Informática na Escola (WIE 2017)

que você espera da sua participação na equipe[Clube de Robótica]?).

\section{Tabela 1. Respostas dos estudantes convidados em relação a expectativa para a participação no Clube de Robótica (2015).}

\begin{tabular}{|l|l|}
\hline 1 & $\begin{array}{l}\text { "Espero que eu seja a complementação das ideias para juntos formemos uma boa } \\
\text { equipe com ideias boas." }\end{array}$ \\
\hline 2 & "Que eu possa ajudar a equipe a cumprir o objetivo." \\
3 & $\begin{array}{l}\text { "Espero que eu possa contribuir no desenvolvimento dos projetos com os meus } \\
\text { conhecimentos e aprender cada vez mais." }\end{array}$ \\
\hline 4 & "Espero ajudar a ter um bom relacionamento com os colegas." \\
\hline 5 & "Espero que seja produtivo de alguma forma" \\
\hline 6 & "Que eu contribua de alguma forma." \\
\hline 7 & "Está ajudando no que precisar." \\
\hline 8 & $\begin{array}{l}\text { "Poder ajudar ao máximo os companheiros da equipe para que juntos possamos } \\
\text { construir algo melhor." }\end{array}$ \\
\hline 9 & "Mais uma mente pensante no meio de outras para que as ideias se encaixem." \\
\hline
\end{tabular}

A relação de cooperação com o clube de robótica enquanto atividade complementar e com os membros pode ser notada nas palavras dos estudantes. Observa-se que existe uma compreensão dos ideais da ação, quando os alunos empregam a palavra "ideia(s)" ou no trecho da resposta em que se expressa "[...]construir algo melhor" e "[...]contribuir no desenvolvimento dos projetos com os meus conhecimentos e aprender cada vez mais.”. É possível notar respostas (6 e 7) que pode indicar um envolvimento mediano e/ou a indecisão na capacidade de contribuição.

Sob a ótica de aspectos educacionais/profissionais, a atividade possibilita a colaboração com a formação técnico-profissional, gerando indivíduos com conhecimento técnico e viabilizando a diversificação no campo de atuação profissional. Aos questionados sobre as expectativas para após o termino do curso técnico em informática, a maior parte dos alunos (6 membros), em uma amostra de 9 membros, indicaram que pretendem ingressar em um curso de graduação, e os demais indicaram querer ingressar no mercado de trabalho.

A quantidade de membros com pretensão ao ingresso na graduação pode gerar uma relevante contribuição as universidades que os atenderem, dado as características da ação do clube em se trabalhar pesquisa científica na educação básica, desenvolvendo nesses membros protagonismo e autonomia ao passo da atividade complementar. O interesse empregado pelos estudantes na ação de desenvolvimento de projetos, que não se apresenta nessa artigo pela limitação de laudas, corresponde a uma transformação nos hábitos do dia a dia pelo entusiasmo como conduzem suas experiências na atividade complementar. Os membros que pensam em concluir o curso e ir para o mercado de trabalho, terão um diferencial nos aspectos que tange o trabalho em equipe, a prática de desenvolvimento de projetos e a experiência em se lidar com a resolução de problemas.

No clube BahiaBot as práticas complementares possibilitam o trabalho de temáticas que muitas vezes não caberiam no currículo escolar ou tornariam inviáveis em meio à metodologia empregada em sala de aula. E assim, as práticas, despertam nos estudantes o interesse em aprender sem que se evidencie uma obrigação. O estudante busca aprender pela vontade e pelo desejo de está em um grupo para aprender, desenvolver competências ou apenas se divertir, tal qual os objetivos expressos na seção 2 para as atividades complementares.

Foram realizados nove encontros com os membros do clube em 2015 e vinte e 
VI Congresso Brasileiro de Informática na Educação (CBIE 2017)

Anais do XXIII Workshop de Informática na Escola (WIE 2017)

seis em 2016. Os encontros foram realizados semanalmente, com duração de 3 horas por encontro. Os procedimentos para a condução das atividades no encontro inicia com uma roda de discussão sobre as ações realizadas pelos membros em grupo ou individual. Os membros do clube apresentam seus avanços aos colegas e em seguida continuam os trabalhos práticos.

Os instrumentos de coletas de dados utilizados, para investigar o desenvolvimento da ação complementar e a verificação do desenvolvimento dos alunos membros do Clube de Robótica, foram questionários, entrevistas semiestruturadas, relatórios de observação participante e coleta de produção dos projetos.

\section{Discussões e Reflexões}

As metodologias empregadas para as atividades do CR devem ofertar através da prática e do diálogo as motivações para que os estudantes sejam capazes de assumir um posicionamento e expor suas ideias, assim como tornar-se agente crítico ao analisar, sintetizar e avaliar soluções para problemas na sociedade. Transferir os estudantes de um pensamento passivo, em que se espera que eles sejam apenas repetidores do que é demonstrado em sala de aula para uma conduta de pensamento crítico e reflexivo são apontados pela aprendizagem ativa e cruciais para a autonomia do estudante.

A Autonomia pode ser expressa e evidenciada, conforme Yus (2004) que posiciona-se sobre fazer conexão entre as aprendizagens escolares com as vivências do indivíduo, que representa aprender com significado. A aprendizagem significativa permite se trabalhar em um contexto complexo e interdisciplinar, tal qual se encontra no mercado de trabalho, por exemplo. Nessa perspectiva, a prática escolar torna-se reflexo dos fatos que contemplam a formação do profissional. Da mesma forma, a aprendizagem ativa é um modelo de aprendizagem que concentra parte da responsabilidade de aprender sobre os estudantes, através de métodos que possibilitam os estudantes buscar e construir seu próprio conhecimento.

Sandra Rodrigues (2015) diz que, a aprendizagem baseada em problema/projeto ou aprendizagem por projeto é uma abordagem pedagógica de caráter ativo que enfatiza as atividades de projeto e tem foco no desenvolvimento de competências e habilidades [Rodrigues 2015], assentando-se sobre a aprendizagem colaborativa e a interdisciplinaridade. A metodologia de Aprendizagem Baseada em Problemas (Problem Based Learning - PBL) [Boud and Feletti 1998], é uma estratégia de aprendizado centrada no estudante, tendo o problema como objeto de motivação e este é independente e interdisciplinar. Dentro dos aspectos característicos da PBL, a interdisciplinaridade é explorada através da busca de soluções aos problemas propostos nessa metodologia. Nesse sentido a interdisciplinaridade é capaz de exercer uma reflexão aprofundada, permitindo a consolidação da autocrítica, o desenvolvimento da pesquisa e inovação [Fazenda 2006]. Para Gadotti (2000), a articulação do saber, conhecimento, vivência, escola, comunidade, meio ambiente etc. é o objetivo da interdisciplinaridade que se traduz na prática por um trabalho coletivo e solidário [Gadotti 2000].

O desenvolvimento de práticas que contextualizem a realidade dos estudantes contribui com a liberdade do pensamento, uma vez que o indivíduo busca na sua experiência uma real significação para o que ensinado. As experiências do indivíduo, que segundo Paulo Freire (1996), deve ser o núcleo da formação da autonomia em si[Freire 1996], e 
VI Congresso Brasileiro de Informática na Educação (CBIE 2017)

Anais do XXIII Workshop de Informática na Escola (WIE 2017)

essa se constrói de forma gradativa no processo decisório de cada sujeito.

O surgimento e aperfeiçoamento de profissões, algumas inexistentes no passado, exigem cada vez mais dos profissionais a capacidade de desenvolver novas habilidades e lidar com as tecnologias em desenvolvimento. Papert (1994) em sua teoria construcionista defende que a habilidade mais importante na determinação do padrão de vida de uma pessoa já se tornou a capacidade de aprender novas habilidades, de assimilar novos conceitos, de avaliar novas situações de lidar com o inesperado. Isso será uma crescente verdadeira no futuro: a habilidade competitiva será a habilidade de aprender [Papert 1994].

Paulo Blikstein (2012) critica escolas por estarem executando práticas obsoletas [Blikstein 2008], que não possibilita aos estudantes demonstrarem suas capacidades e talentos. Blikstein, como Freire (1996), percebe no protagonismo do indivíduo um viés para seu crescimento social e intelectual, e assim como Papert (1994), acredita que as tecnologias digitais são uma das mais poderosas ferramentas de expressão intelectual e artística criadas pela humanidade.

Ainda que as instituições de ensino venham mudando, essa transformação ocorre em um processo lento. De um lado, escolas têm buscado investir em recursos educacionais que possibilitem melhor "transmissão" de conhecimentos, e do outro, o professor que se encontra indisponível para se adequar aos novos recursos. Porém, esse quadro também pode ser inverso, o professor está preparado para incluir em suas disciplinas recursos para sair de tal obsolência, mas a escola não busca adquiri-los. Tomando como base a primeira situação, as atividades complementares apresentariam uma solução ao problema como, por exemplo, a criação de organizações de estudantes que viabilizem o compartilhamento de conhecimentos entre alunos em diversos assuntos.

O Clube de Robótica, enquanto organização de estudantes, busca resgatar a autonomia na aprendizagem e as práticas do "aprender fazendo" através do desenvolvimento de robôs e sistemas autônomos com a finalidade de resolver problemas que apresentam relevância social ou desafios que os aproximam do "fazer ciência". O conceito de clube torna todos os participantes membros, que diferente do status de aluno permite o protagonismo, pois participam de decisões, expõem seus interesses relacionados aos saberes que desejam construir e são corresponsáveis por essa caminhada. Neste caso, o estudante se debruça sobre o conhecimento que almeja e compreende o seu papel no processo de aprendizagem. Conforme menciona Pierre Lévy (1994) novas maneiras de pensar e conviver estão sendo elaboradas no mundo das telecomunicações e informática [Lévy 1993]. Sob ações de pensamento e convivência, a robótica empregada como um meio de reconhecimento de habilidades e desenvolvimento de competências que tende a possibilitar maior interação social e o aumento da aprendizagem em torno das atividades realizadas pelo Clube de Robótica.

\section{Considerações Finais}

Experiências do clube de robótica enfatizam que a robótica em atividades complementares ou, as que ocorrem dentro das disciplinas de um curso, exercem um papel fundamental no desenvolvimento dos estudantes. A proposta de clube ao invés de curso ou oficina se baseia no protagonismo juvenil, no qual o estudante é membro do clube e exerce sua autonomia e autoconfiança para trilhar o seu próprio caminho.

Os clubes em sua perspectiva complementar, propõe um intercâmbio de suas ações 
e aprendizados com os componentes curriculares do ambiente escolar. Essa interação pode ocorrer de forma direta ou indireta, contudo apresentam possibilidades de envolvimento dos educandos nesse processo de complementação de uma prática sócioeducacional. Seja como atividade lúdica, ou que desempenham o desenvolvimento intelectual, o Clube de Robótica traduz em suas ações uma vitalização do processo de ensino, por depender da vontade e interesse dos estudantes, protagonismo e autonomia, para que a ação desempenhe um papel significativo em seu contexto de vida.

Contribuir na ação educacional através de uma prática complementar como o Clube de Robótica tem mostrado resultados, seja na expectativa dos estudantes envolvidos ou mesmo nas ações realizadas, construção de projetos robóticos e participação em eventos científicos. Envolver os estudantes em seu próprio contexto e evidenciar as razões para o trabalho desenvolvido foi um dos fatores que são previstos na ação do Clube de Robótica e que expõe uma das características dessa prática.

Possibilitar que estudantes tenham maior ganho em aprendizagem e aproveitamento escolar através do protagonismo, despertando sua autonomia e autoconfiança, que a prática complementar dos Clubes de Robótica propõem, os incentivando à produção e participação de eventos científicos, ajudando no processo de construção do conhecimento seja para o ingresso no ensino superior ou no mercado de trabalho, e ainda na associação desse conhecimento com suas experiências.

Os clubes de robótica, como atividades complementares, estabelecem um ambiente democrático, possibilita a seus participantes serem membros, numa participação genuína para que desempenhem sua autonomia, autoconfiança e autodeterminação.

\section{Referências}

Almeida, M. E. B. (2005). Integração das Tecnologias na Educação, chapter Tecnologia, currıculo e projetos: Prática e formação de professores na integração de mÍdias. Ed. Salto para o futuro.

Alves, A. C., Blikstein, P., and de Deus Lopes, R. (2005). Robótica na periferia? uso de tecnologias digitais na rede pública de são paulo como ferramentas de expressão e inclusão. In Anais do Workshop de Informática na Escola, volume 1.

Alves, N. (2000). Cultura e cotidiano escolar. SciELO Brasil.

Assmann, H. (1998). Reencantar a educação: rumo à sociedade aprendente. Vozes.

Benitti, F. B. V. (2012). Exploring the educational potential of robotics in schools: A systematic review. Computers \& Education, 58(3):978-988.

Blikstein, P. (2008). Travels in troy with freire: Technology as an agent for emancipation.

Boud, D. and Feletti, G. (1998). The challenge of problem-based learning. Psychology Press.

Bustamante, S. B. V. (2003). "hands on"\&"heads in": trabalhando com a robótica em educação. In Anais do Workshop de Informática na Escola, volume 1, pages 197-203.

Caldas, R. F. L. and Hübner, M. M. C. (2001). O desencantamento com o aprender na escola: o que dizem professores e alunos. Revista Psicologia-Teoria e Prática, 3(2). 
VI Congresso Brasileiro de Informática na Educação (CBIE 2017)

Anais do XXIII Workshop de Informática na Escola (WIE 2017)

Charao, A. S., Patrıcia, P. d. A., de Azevedo, B. R., and Lima, J. C. D. (2015). Clube de computação para alunos de ensino médio: um relato de experiência. Anais WEI / Congresso Sociedade Brasileira da Computação.

Costa, A. C. G. d. and Vieira, M. A. (2000). Protagonismo juvenil: adolescência, educação e participação democrática. Salvador: Fundação Odebrecht, 332.

Dias, J., Abdalla, D., and Saba, H. (2015). Ensino da robótica livre como instrumento de aprendizado interdisciplinar na rede pública de educação profissional e tecnológica. In Anais WEI / Congresso Sociedade Brasileira da Computação.

Fassbinder, A. G. d. O. (2012). Experiências no estímulo à prática de programação através do desenvolvimento de atividades extracurriculares relacionadas com as competições de conhecimentos. In WEI - Congresso da Sociedade Brasileira de Computação $(C S B C)$, page 48 .

Fazenda, I. C. A. (2006). Interdisciplinaridade: história, teoria e pesquisa. Papirus editora.

Freire, P. (1996). Pedagogia da autonomia: saberes necessários à prática docente. São Paulo: Paz e Terra.

Gadotti, M. (2000). Perspectivas atuais da educação. volume 14, pages 03-11. SciELO Brasil.

Lévy, P. (1993). As tecnologias da inteligência:o futuro do pensamento na era da informática. Editora 34. Tradução de: Carlos Irineu da Costa.

Nérici, I. (1967). Atividades extraclasse na escola média. Fundo de Cultura SA.

Papert, S. (1994). A máquina das crianças: repensando a escola na era da informática. Ed. ArtMed.

Rodrigues, S. (2015). Metodologias ativas: O que é aprendizagem baseada em projeto. Disponível em: http://goo.gl/Fa4Kan. Acesso em 02. Mar. 2017.

Yus, R. and de Moraes, D. V. (2002). Educação integral: uma educação holística para o século XXI. Artmed. 